\title{
OBSERVATIONS OF LUNI-SOLAR AND FREE CORE NUTATION
}

Dennis D. McCarthy

Brian J. Luzum

U. S. Naval Observatory

Washington, DC 20392 USA

ABSTRACT. An analysis of the differences between observed nutation angles and the 1980 IAU Nutation Theory shows the existence of currently unmodeled effects. An empirical set of corrections to the 1980 IAU Nutation Theory is presented and compared with current geophysical models. A prograde periodic variation (period $\approx 420$ days), which may be related to the theoretical free core nutation, is apparently seen.

\section{Introduction}

The nutational motion of the Earth's axis of figure is modeled by theories based initially on descriptions of the motion of a rigid Earth caused by luni-solar torques (Woolard 1953, Kinoshita 1977, Zhu and Groten 1989, Souchay and Kinoshita 1990). Corrections computed from geophysical theories (Wahr 1981, Molodenskiy and Kramer 1987, Mathews et al. 1989, Dehant 1990, Zhu et al. 1990) are applied to the rigid Earth models in order to produce non-rigid Earth nutation models (e. g. ZMOA-1990 in Herring 1990) describing the actual motion of the Earth more closely.

The International Earth Rotation Service (IERS) Standards (McCarthy 1989) recommends the use of the 1980 IAU Nutation Theory (Seidelmann 1982) based on the Wahr model (Wahr 1981). However, astronomical observations made by using Very Long Basline Interferometry (VLBI) and Lunar Laser Ranging (LLR) of the nutation angles $\psi$ (longitude) and $\epsilon$ (obliquity) show discrepancies ( $d \psi$ and $d \epsilon$ ) with the model.

Complicating the analysis of the observations is the possible existence of the free core nutation (FCN), which has sometimes been referred to as the nearly diurnal free wobble. This motion, due to the rotating, elliptical, fluid core, should appear, according to Sasao and Wahr (1981) as a retrograde periodic variation in nutation with a period of about 460 sidereal days.

\section{Nutation Observations}

The observations of $d \psi$ and $d \epsilon$ from the CALC 7.1 solution of International Radio Interferometric Surveying (IRIS) five-day VLBI data set, as provided by the National Geodetic Survey (NGS) (NEOS Annual Report for 1989, p. 3), were used. Nutation observations from the CALC 7.1 solution of the Crustal Dynamics Project (CDP) VLBI data set, as provided by the National Aeronautics and Space Administration (NASA) at Goddard Space Flight Center, were also utilized (IERS Annual Report for 1989). NASA made two 
VLBI solutions: one with the plate motion fixed and one with the plate motion treated as a "solve for" variable.

Nutation coefficients can also be obtained from LLR observations (Williams et a1. 1990). These coefficients are not produced for every observation, as is the case with the VLBI data, but are instead produced when a global solution is made. Due to the sparse nature of the LLR data, it is not possible to determine a full set of nutation coefficients. However, the long span of data makes it useful in the attempt at separating the precession term from the main 18.6-year nutation term.

\section{Computation of Nutation Coefficients}

In step 1 , the separate VLBI solutions were used in simultaneous leastsquares solutions to determine a bias, rate, and corrections to the primary 18.6-year periodic term in nutation for both $d \psi$ and $d \epsilon$ for each series. In step 2, the observations are adjusted by the corrections found in step 1 and a solution is made for the high-frequency (periods less than nine years) terms only. Final estimates were then obtained by iterating steps 1 and 2 for the long- and short-period terms, including the 420-day term, until convergence was obtained.

When the final nutation coefficients were determined for each of the VLBI series, they were combined with the coefficients provided by LLR (Williams et al. 1990). In this combination, the results from only one NASA series (the fixed) were included to avoid overweighting the NASA CDP solution. As can be seen in Tables II, III, and IV, there is no significant difference between the two NASA CDP series. A weighted mean was computed for each of the coefficients, where the weight is the inverse square of the formal error. The results are shown in Tables I, II, and III. The error listed is a combination of the internal errors of the contributors to the mean and the standard error of the weighted mean. There appear to be significant unexplained differences between VLBI and LLR coefficients.

Table I. Correction in bias and slope to the $\mathrm{d} \psi$ and $\mathrm{d} \epsilon$ found from the analysis of the VLBI and the LLR nutation series. The units of the coefficients are msec. of arc for bias and msec. of arc/century for slope.

\begin{tabular}{|c|c|c|c|c|c|}
\hline$d \phi$ & IRIS & NASA (Fixed) & NASA (Froe) & LIR & MEAN \\
\hline $\begin{array}{l}\text { Bias } \\
\text { Slope }\end{array}$ & $\begin{array}{r}-37.2 \pm 2.5 \\
-274.6 \pm 17.6\end{array}$ & $\begin{array}{r}-38.6 \pm 3.1 \\
-295.0 \pm 21.3\end{array}$ & $\begin{array}{r}-37.7 \pm 3.1 \\
-288.8 \pm 21.2\end{array}$ & $-280 \pm 50$ & $\begin{array}{r}-37.8 \pm 2.1 \\
-282.7 \pm 14.8\end{array}$ \\
\hline$d$ & & & & & \\
\hline $\begin{array}{l}\text { Bias } \\
\text { Slope }\end{array}$ & $\begin{array}{r}-5.1 \pm 0.9 \\
-11.1 \pm 6.5\end{array}$ & $\begin{array}{l}-4.6 \pm 1.4 \\
-6.8 \pm 9.9\end{array}$ & $\begin{array}{r}-5.2 \pm 1.4 \\
-11.0 \pm 9.8\end{array}$ & & $\begin{array}{l}-5.0 \pm 0.8 \\
-9.8 \pm 5.8\end{array}$ \\
\hline
\end{tabular}




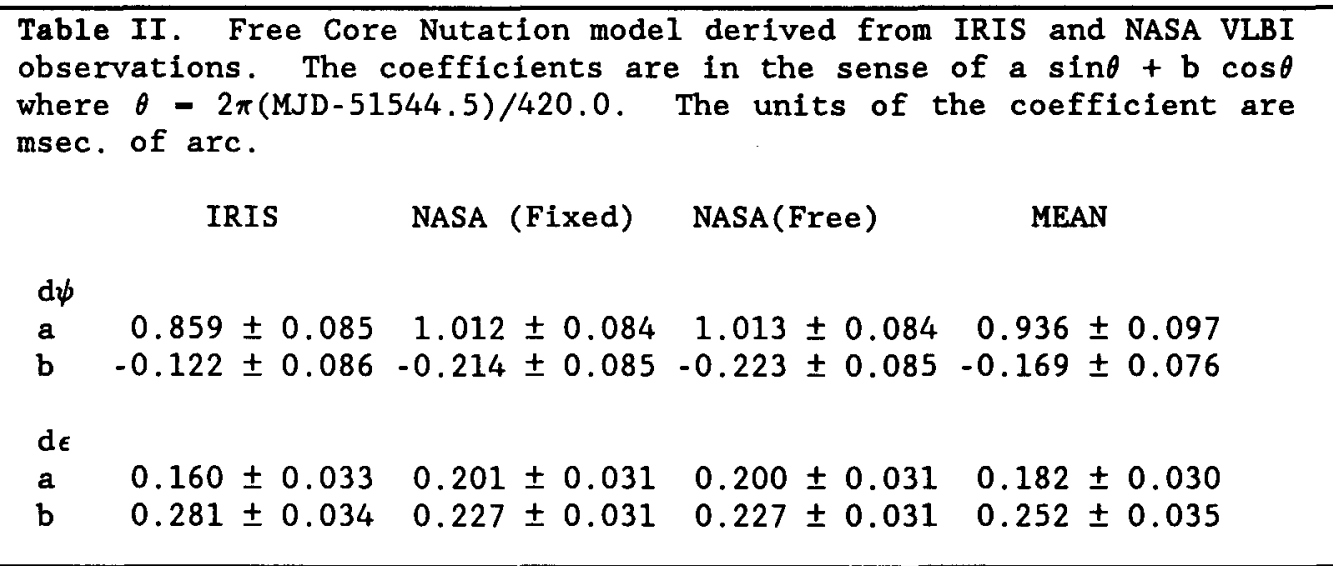


Table III. Corrections to the nutation terms $\mathrm{d} \psi$ and $\mathrm{d} \epsilon$ found from the analysis of the VLBI and the LLR solutions. The units of the coefficients are msec. of arc.

CORRECTIONS IN LONGITUDE

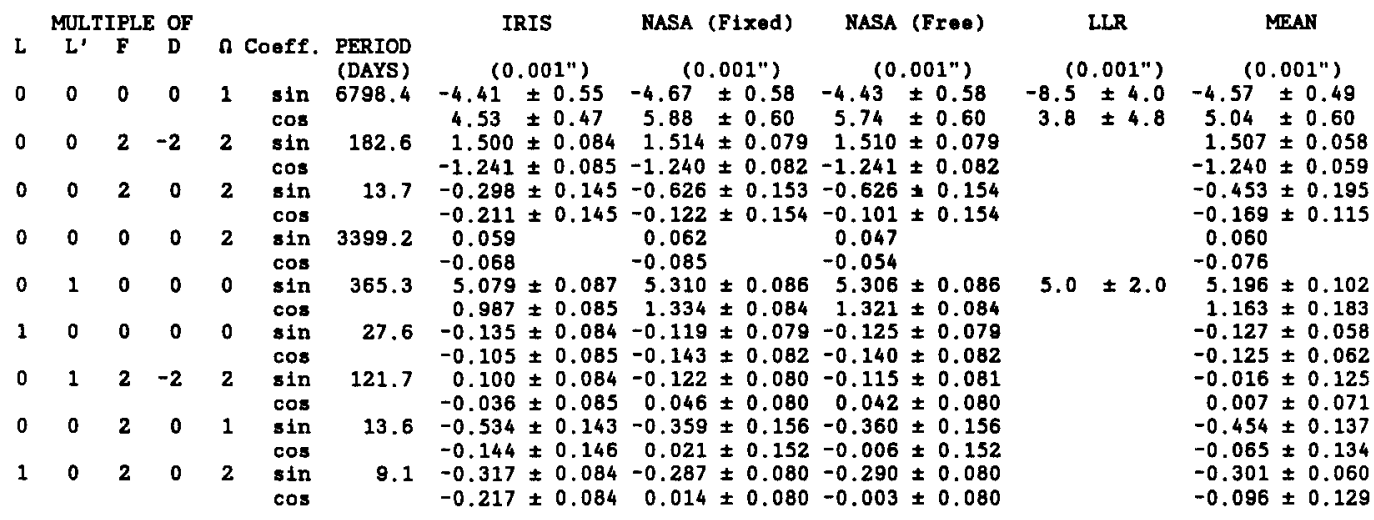

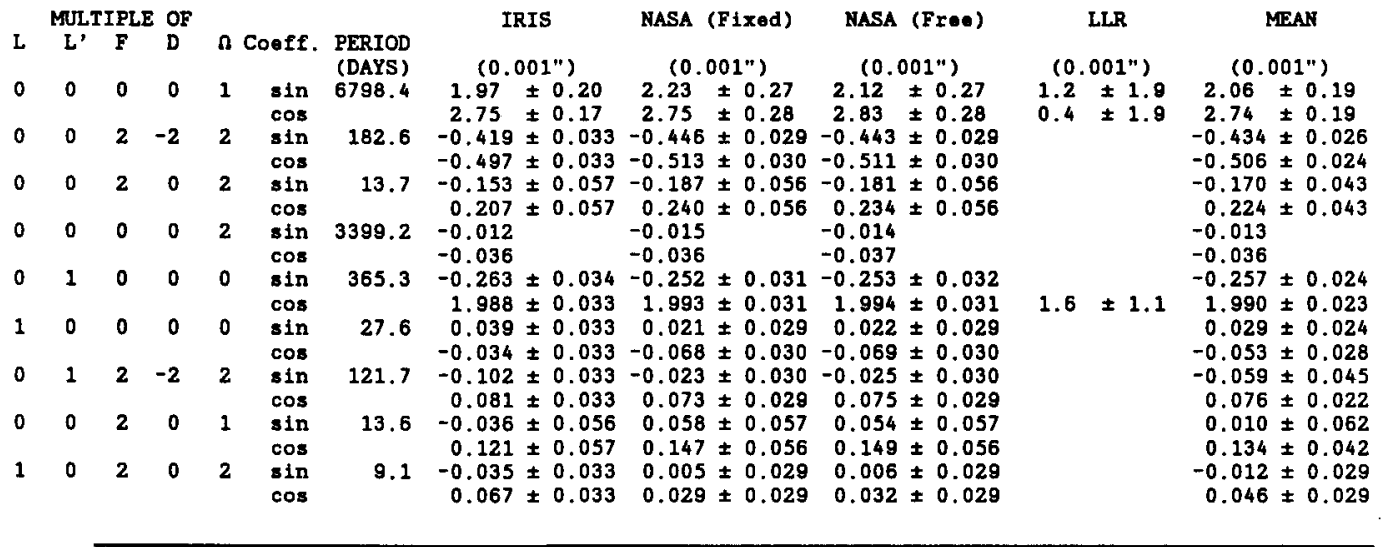

\section{Comparisons}

Table IV compares the observed corrected constants with theoretical rigid and non-rigid Earth values of various authors. Recall that the nutation angles can be represented by

$$
\begin{aligned}
& \psi=\psi_{r} \sin \theta+\psi_{1} \cos \theta, \\
& \epsilon=\epsilon_{r} \cos \theta+\epsilon_{1} \sin \theta,
\end{aligned}
$$


where $\psi_{r}$ and $\epsilon_{r}$ correspond to the estimates shown in Table IV. Here, $\theta$ represents any of the principal angular nutation arguments.

Table IV. Comparison of theoretical models with the observed values. Note that the models of Kinoshita and Kinoshita and Souchay are for a rigid Earth. The column labelled IAU lists the 1980 IAU Nutation Theory coefficients. The units are sec. of arc.

$\psi_{r}$

\begin{tabular}{|c|c|c|c|c|c|c|c|c|}
\hline $\begin{array}{r}\text { Period } \\
\text { (days) } \\
9.1 \\
13.6 \\
13.7 \\
27.6 \\
121.7 \\
182.6 \\
365.3 \\
3399.2 \\
6798.4\end{array}$ & $\begin{array}{r}\text { Kinoshita } \\
-0.0296 \\
-0.0378 \\
-0.2215 \\
0.0678 \\
-0.0500 \\
-1.2775 \\
0.1255 \\
0.2079 \\
-17.2815\end{array}$ & $\begin{array}{c}\text { Kinoshita } \\
\text { \& Souchay } \\
-0.0296 \\
-0.0379 \\
-0.2216 \\
0.0678 \\
-0.0498 \\
-1.2732 \\
0.1255 \\
0.2090 \\
-17.2807\end{array}$ & $\begin{array}{r}-0.0301 \\
-0.0386 \\
-0.2274 \\
0.0712 \\
-0.0517 \\
-1.3187 \\
0.1426 \\
0.2062 \\
-17.1996\end{array}$ & $\begin{array}{l}\text { This } \\
\text { Paper } \\
-0.0304 \\
-0.0391 \\
-0.2279 \\
0.0711 \\
-0.0517 \\
-1.3172 \\
0.1478 \\
0.2063 \\
-17.2042\end{array}$ & $\begin{array}{r}Z M O A \\
1990 \\
-0.0301 \\
-0.0387 \\
-0.2276 \\
0.0711 \\
-0.0517 \\
-1.3172 \\
0.1476 \\
0.2075 \\
-17.2063\end{array}$ & $\begin{array}{c}\text { Molodenskiy } \\
\text { Kramer } \\
-0.0302 \\
- \\
-0.2275 \\
0.0711 \\
-0.0517 \\
-1.3178 \\
0.1472 \\
0.2062 \\
-17.2058\end{array}$ & $\begin{array}{c}\text { Dehant } \\
- \\
- \\
-0.2260 \\
- \\
- \\
-1.3138 \\
0.1464 \\
- \\
-17.2097\end{array}$ & $\begin{array}{r}\text { Zhu \& } \\
\text { Groten } \\
-0.0302 \\
-0.0389 \\
-0.2282 \\
0.0712 \\
-0.0518 \\
-1.3172 \\
0.1474 \\
0.2074 \\
-17.2062\end{array}$ \\
\hline
\end{tabular}

$\epsilon_{r}$

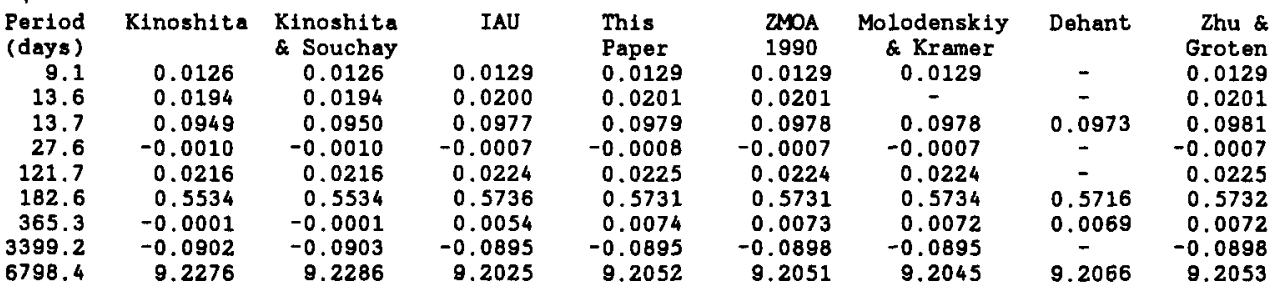

\section{Discussion}

The large unexplained differences between the coefficients derived from VLBI and those derived from LLR point to the possibility of systematic errors in both techniques. Ignoring possible systematic errors, then, it would appear that VLBI observations of the major components of the variation of $\psi \sin \epsilon_{0}$ and $\epsilon$ are precise to better than $\pm 0.1 \mathrm{msec}$. of arc. Combining VLBI and LLR results shows that the accuracy of the derived nutation coefficients is better than $\pm 1.0 \mathrm{msec}$. of arc.

The 420-day term is included because it is statistically significant in the analysis of the residuals. One might suspect that this is evidence for the FCN, which would be expected to contribute a variation in the observations with a period of about 460 sidereal days. The observed motion is mainly prograde, contrary to the expected motion (Sasao and Wahr 1981) with the prograde amplitude being $0.33( \pm 0.03) \mathrm{msec}$. of arc and the retrograde being $0.08( \pm 0.03) \mathrm{msec}$. of arc. Herring (1987) mentions the FCN term but finds that its amplitude is too small to be included in his solution. Zhu, et al. (1990) finds a 433.2-day term which they call free core nutation. Additional study is necessary to explain the difference 
in observed direction of rotation in the FCN term between theory and observation.

\section{Conclusion}

The solution for luni-solar nutation presented here combines VLBI and LLR observations. The rms of the fit with respect to the observations in $\psi$ sin $\epsilon_{0}$ and $\epsilon$ are at the level of about \pm 0.6 milliseconds of arc. Accuracy of the derived constants, as well as the agreement between the fit to the observations and theory, seems to be at the level of about \pm 1.0 millisecond of arc in $\psi \sin \epsilon_{0}$ and $\epsilon$.

Using only data from MJD 45700 (January 1984), a prograde "free core nutation" term is found with a period of 420 days and amplitude of 0.33 msec. of arc.

\section{References}

Dehant, V.: 1990, Geophys. J. Int. 100, 477.

Herring, T.: 1987, In BIH Annual Report for 1987, pp. D-106-D108.

Herring, T.: 1990, to be published.

Herring, T. A., Gwinn, C. R., and Shapiro, I. I.: 1986, J. Geophys. Res. 91,4745 .

Kinoshita, H.: 1977, Celest. Mech. 15, 277.

Kinoshita, H. and Souchay, J.: 1990, Submitted to Celest. Mech.

McCarthy, D. D.: 1989, IERS Tech. Note 3, 14.

Mathews, P. M., Buffett, B. A., Herring, T. A., and Shapiro, I. I.: 1989, Submitted to $J$. Geophys. Res.

Molodenskiy, S. M. and Kramer, M. V.: 1987, Izvest., Earth Phys. 23, 8 . NEOS Annual Report for 1987

Sasao, T. and Wahr, J. M.: 1981, Geophys. J. R. Astron. Soc. 64, 729.

Seidelmann, P. K.: 1982, Celest. Mech. 27, 79.

Wahr, J. M.: 1981, Geophys. J. R. Astron. Soc. 64, 705.

Williams, J. G., Newhall, X. X., and Dickey, J. O.: 1990, Submitted to Astron. and Astrophys. Let.

Woolard, E. W.: 1953, Astron. Pap. Amer. Eph. and Naut. Almanac 15, part 1.

Zhu, S. Y., and Groten, E.: 1989, Astron. J. 98, 1104.

Zhu, S. Y., Groten, E., and Reigber, C.: 1990, Astron. J. 99, 1024. 